\title{
Inferior Vena Cava Filter Fragmentation, Embolization and Erosion through the Vessel Wall: An Unusual Complication
}

\author{
Mimi Denning, Vincent Cisternino, Kaitlin Willems, Coney Bae, Peter Grzesik, Rebecca Rigolosi, Scot D Henry, Lisa M Cannon and James V Guarrera*
} Center for Liver Disease and Transplantation, Department of Surgery, Columbia University Medical Center, New York, NY, USA

*Corresponding author: James V Guarrera, Associate Professor of Surgery, Surgical Director of Adult Liver Transplantation, Center for Liver Disease and Transplantation, Columbia University College of Physicians and Surgeons, 622 West 168th Street, PH 14 Center, Room 202, New York, NY 10032, USA, Tel: +1 212-305-4199; Fax: +1 212-305-8710; E-mail: scothenry.phd@gmail.com

Rec date: May 08, 2014; Acc date: June 07, 2014; Pub Date: June 09, 2014

Copyright: $\odot 2014$ Denning M, et al. This is an open-access article distributed under the terms of the Creative Commons Attribution License, which permits unrestricted use, distribution, and reproduction in any medium, provided the original author and source are credited.

\begin{abstract}
Pulmonary embolism is a frequently fatal form of venous thromboembolism that is often avoided with the placement of an Inferior Vena Cava (IVC) filter. Although these filters have low complication rates, filter migration, caval occlusion, and filter fragmentation can occur. Filter strut perforation of the IVC lumen is a frequent occurrence and is typically asymptomatic. We report a case of filter fragmentation with subsequent strut migration and perforation, extending out of the IVC lumen and penetrating into the surrounding vascular and connective tissues as well as into the inferomedial aspect of the left lower lung lobe and the right atrium causing significant abdominal and back pain. The patient underwent operative retrieval of the filter.
\end{abstract}

Keywords: Inferior vena cava; Inferior vena cava filter; Fragmentation; Filter migration

\section{Introduction}

Venous Thromboembolism (VTE) is a common disease in the United States with significant risk of mortality. Pulmonary Embolism (PE) is diagnosed in over 355,000 patients per year and results in approximately 244,000 deaths [1]. Indications for VTE prevention and IVC filter insertion in orthopedic patients are clearly written in the $9^{\text {th }}$ edition of the ACCP Guidelines published in 2012, include; contraindications to anticoagulation, failure of ongoing anticoagulant therapy with a known PE or deep vein thrombosis (DVT), high risk trauma, free floating venous thrombus, pulmonary thromboendarterectomy for chronic thromboembolic pulmonary hypertension, thombolytic therapy for DVT [2]. However despite these guidelines, there has been an increase in the number of IVC filters inserted, largely due to the advent and development of the retrievable or removable filter [3]. A study by Stein, Kayali and Olson show an increase in use of IVC filters within the last twenty (20) years in patients both with and without diagnosed deep veined thrombosis and/or pulmonary embolism [4]. Duszak, Parker, Levin and Rao echo this finding in their study of Medicare patients which showed that filter insertion has doubled over the last ten years [5]. In most clinical scenarios anticoagulation is the preferred method of pulmonary embolism prevention. However, when anticoagulation is contraindicated [2], transvenous IVC filter placement is the recommended standard of care [6]. Although protrusion of IVC filter struts outside of the IVC lumen has been reported in up to $40 \%$ of cases [7], these cases are often asymptomatic and, typically, IVC filter insertion is considered a low-risk procedure with a major complication risk of only $0.3 \%$. Possible complications include filter migration, caval occlusion, and filter fragmentation [8]. We report a case of IVC filter fragmentation with subsequent strut migration to the right atrium with deep penetration of the septal leaf of the tricuspid valve and filter strut penetration of the right common iliac artery and the lumbar vertebral body.

\section{Case Report}

In 2005, a 19 year old woman fell from a fourth story window and sustained left hip and femur fractures and a pneumothorax. She was treated at another center with an open reduction/internal fixation, a tube thoracostomy, and an IVC filter of unidentified type (possibly Gunther Tulip, OptionELITE, or ALN type) was preemptively placed. In April of 2009 she presented to a local hospital with complaints of right-sided chest pain and right hand pain. She described symptoms, worsening in severity over a six-month period, of occasional "sharp, knife-like" right-sided chest pain that escalated in intensity with deep inspiration. A chest X-ray revealed a foreign body in the thorax, and a computed tomography (CT) scan of the chest, abdomen and pelvis revealed a fractured IVC filter and foreign bodies in the inferomedial aspect of the left lower lung lobe and the right atrium. The vascular and cardiothoracic surgery services were consulted. The decision was made to leave the IVC filter in place. Furthermore, there was no indication to remove the fragment in the atrium, as its position was similar to pacing leads frequently placed in cardiac surgery. The patient was discharged but presented to our Emergency Department in May of 2009. A repeated chest CT revealed metallic foreign bodies within the left lower lung lobe and in the right atrium. The IVC filter was seen below the level of the renal veins. Several filter struts extended horizontally and posteriorly and one extended anteriorly (Figures 1-3). Multiple filter struts protruded from the lumen of the IVC. A medial sternotomy with removal of the foreign body was performed. The procedure revealed a bent metallic wire, measuring 2.5 $\mathrm{cm}$ in length and less than $0.1 \mathrm{~cm}$ in diameter in the right atrium, deeply embedded in the leaflets of the tricuspid valve. The patient was discharged eight days later. In June of 2011 the patient returned to the Emergency Department for increasing frequency of severe 'shooting' mid-abdominal and lower back pain. The patient was admitted and an exploratory laparotomy that resulted in a filter removal. The IVC was 
Citation: Denning M, Cisternino V, Willems K, Bae C, Grzesik P, et al. (2014) Inferior Vena Cava Filter Fragmentation, Embolization and Erosion through the Vessel Wall: An Unusual Complication. J Vasc Med Surg 2: 142. doi:10.4172/2329-6925.1000142

Page 2 of 3

exposed from the bifurcation to just below the renal veins. The IVC filter struts had eroded out of the IVC into the periureteric tissue, the right common iliac artery and posteriorly into the lumbar periosteum. A long longitudinal cavotomy allowed the removal of the filter. The protruding barbs were trimmed with wire cutter and the remaining filter was removed intact.

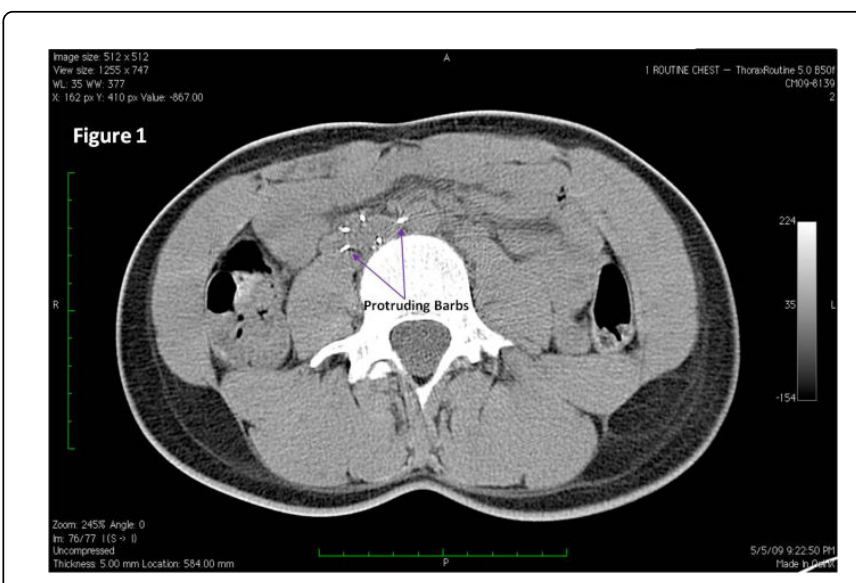

Figure 1: Horizontally Extended Filter struts

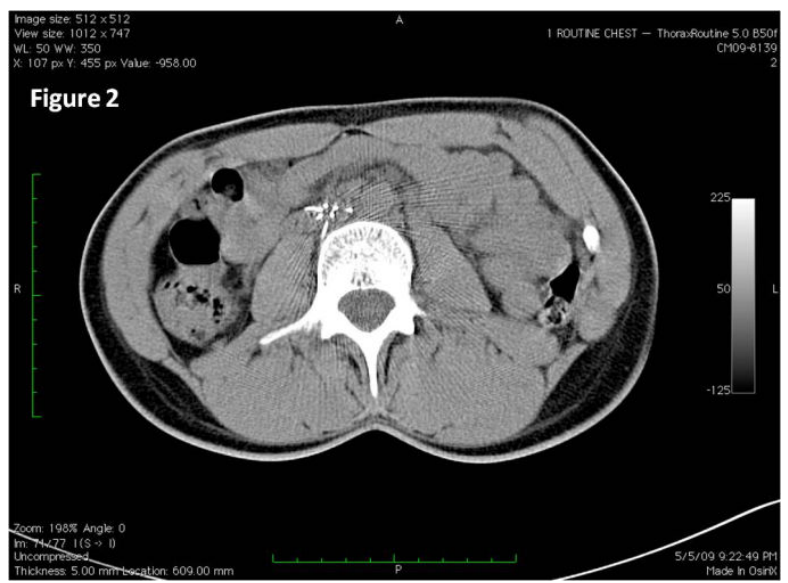

Figure 2: Posteriorly Extended Filter struts

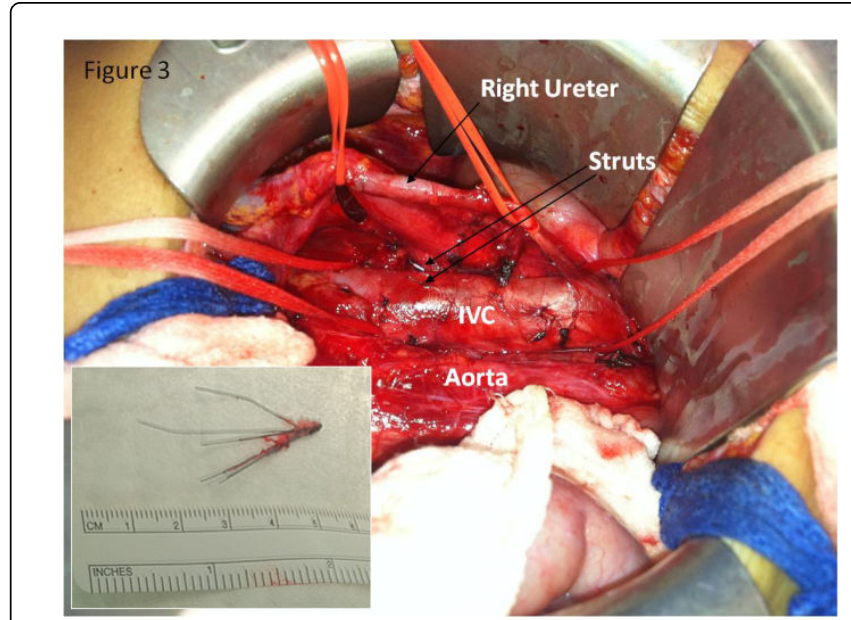

Figure 3: Anteriorly Extended Filter struts

\section{Discussion}

IVC filters are a primary method of prevention of venous thromboembolism when anticoagulation therapy is contraindicated. The IVC filters' higher risk of recurrent deep vein thrombosis relegates it to a second line role [9]. Despite the safety and efficacy of IVC filter placement, perforation of the IVC by filter struts is common. In a prior study, CT images of filters placed between 1 and 880 days prior to imaging revealed an $86 \%$ perforation rate. When only filters placed longer than 71 days prior to imaging were considered, $100 \%$ perforation rates were observed [10]. Regardless of the normally asymptomatic nature of strut perforation of the IVC wall, it has been associated with an increased risk of filter fragmentation [11]. Thus, filter perforation is not a contraindication to filter retrieval [12]. Our case demonstrates that filter fragmentation and fistulization may lead to significant morbidity and need for reoperation. In this case, strut erosion was symptomatic and penetrated into multiple surrounding structures which prompted mini-laparotomy and open retrieval. We believe this more invasive approach is warranted in atypical symptomatic cases of strut perforation into multiple surrounding structures such as the left lower lung lobe and the right atrium, the aorta, prevertebral fascia and periureteric tissue. This approach allows prompt diagnosis and repair of injuries to these structures in a controlled setting. IVC filter strut perforation should be included on the differential diagnosis of patients presenting with unexplained pain and indwelling IVC filters.

\section{References}

1. Streiff MB (2000) Vena caval filters: a comprehensive review. Blood 95: 3669-3677.

2. Rajasekhar A, Streiff MB (2013) Vena cava filters for management of venous thromboembolism: a clinical review. Blood Rev 27: 225-241.

3. Sing RF, Fischer PE (2013) Inferior vena cava filters: indications and management. Curr Opin Cardiol 28: 625-631.

4. Stein PD, Kayali F, Olson RE (2004) Twenty-one-year trends in the use of inferior vena cava filters. Arch Intern Med 164: 1541-1545.

5. Duszak R Jr, Parker L, Levin DC, Rao VM (2011) Placement and removal of inferior vena cava filters: national trends in the medicare population. J Am Coll Radiol 8: 483-489. 
Citation: Denning M, Cisternino V, Willems K, Bae C, Grzesik P, et al. (2014) Inferior Vena Cava Filter Fragmentation, Embolization and Erosion through the Vessel Wall: An Unusual Complication. J Vasc Med Surg 2: 142. doi:10.4172/2329-6925.1000142

Page 3 of 3

6. Johnson MS, Nemcek AA Jr, Benenati JF, Baumann DS, Dolmatch BL, et al. (2010) The safety and effectiveness of the retrievable option inferior vena cava filter: a United States prospective multicenter clinical study. J Vasc Interv Radiol 21: 1173-1184.

7. Woodward EB, Farber A, Wagner WH, Cossman DV, Cohen JL, et al (2002) Delayed retroperitoneal arterial hemorrhage after inferior vena cava (IVC) filter insertion: case report and literature review of caval perforations by IVC filters. Ann Vasc Surg 16: 193-196.

8. Shang EK, Nathan DP, Carpenter JP, Fairman RM, Jackson BM (2011) Delayed complications of inferior vena cava filters: case report and literature review. Vasc Endovascular Surg 45: 290-294.

9. Decousus H, Leizorovicz A, Parent F, Page Y, Tardy B, et al. (1998) A clinical trial of vena caval filters in the prevention of pulmonary embolism in patients with proximal deep-vein thrombosis. Prevention du
Risque d'Embolie Pulmonaire par Interruption Cave Study Group. The New England journal of medicine 338: 409-415.

10. Durack JC, Westphalen AC, Kekulawela S, Bhanu SB, Avrin DE, et al. (2012) Perforation of the IVC: rule rather than exception after longer indwelling times for the Gunther Tulip and Celect retrievable filters. Cardiovasc Intervent Radiology 35: 299-308.

11. Hull JE, Robertson SW (2009) Bard Recovery filter: evaluation and management of vena cava limb perforation, fracture, and migration. J Vasc Interv Radiol 20: 52-60.

12. Oh JC, Trerotola SO, Dagli M, Shlansky-Goldberg RD, Soulen MC, et al. (2011) Removal of retrievable inferior vena cava filters with computed tomography findings indicating tenting or penetration of the inferior vena cava wall. J Vasc Interv Radiol 22: 70-74. 